\title{
Bending Analysis of a Filament-Wound Composite Tube
}

\author{
Gyula Szabó, Károly Váradi, Dávid Felhős \\ Department of Machine and Product Design, Budapest University of Technology and Economics, Budapest, Hungary \\ Email:szabo.gyula@gt3.bme.hu
}

How to cite this paper: Szabó, G., Váradi, K. and Felhős, D. (2018) Bending Analysis of a Filament-Wound Composite Tube. Modern Mechanical Engineering, 8, 66-77. https://doi.org/10.4236/mme.2018.81005

Received: August 31, 2017

Accepted: February 25, 2017

Published: February 28, 2018

Copyright (C) 2018 by authors and Scientific Research Publishing Inc. This work is licensed under the Creative Commons Attribution International License (CC BY 4.0).

http://creativecommons.org/licenses/by/4.0/

\begin{abstract}
The aim of this paper is to present finite element model of a filament-wound composite tube subjected to three-point bending and bending in accordance with standard EN 15807:2011 (railway applications-pneumatic half couplings) along with its experimental verification. In the finite element model, composite reinforcement plies have been characterized by linear orthotropic material model, while rubber liners have been described by a two-parameter MooneyRivlin model. Force-displacement curves of three-point bending show fairly good agreement between simulation results and experimental data. Reaction forces of FE simulation and experiment of standard bending test are in good agreement.
\end{abstract}

\section{Keywords}

Filament-Wound Composite Tube, Three-Point Bending Test, Bending Analysis, Finite Element Model

\section{Introduction}

Composite tubes are utilized in a variety of engineering fields due to their high specific strength and high specific stiffness [1]. The most widespread manufacturing process of composite tubes is filament-winding because of high fibre precision, high fibre content, low void content and good automation capability [2]. The most commonly encountered operational loads are uniaxial tension, internal pressure, biaxial tension (combined uniaxial tension and internal pressure), and bending. The most frequently applied winding angle is $\pm 55^{\circ}$, which is the optimal winding angle related to biaxial tension, where hoop-to-axial stress ratio is 2:1. If only internal pressure is applied, the optimal winding angle is $\pm 75^{\circ}$ [3].

General structure of composite tubes can be seen in Figure 1. The included angle of yarns and the axis of the tube is the winding angle (or orientation angle) 


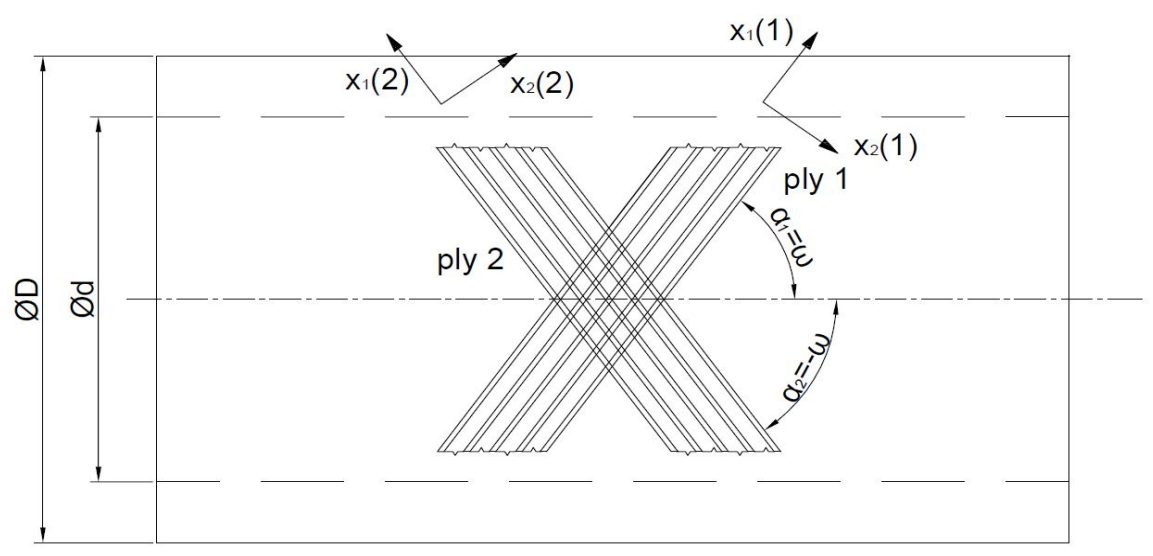

Figure 1. Structure of the composite tube [4].

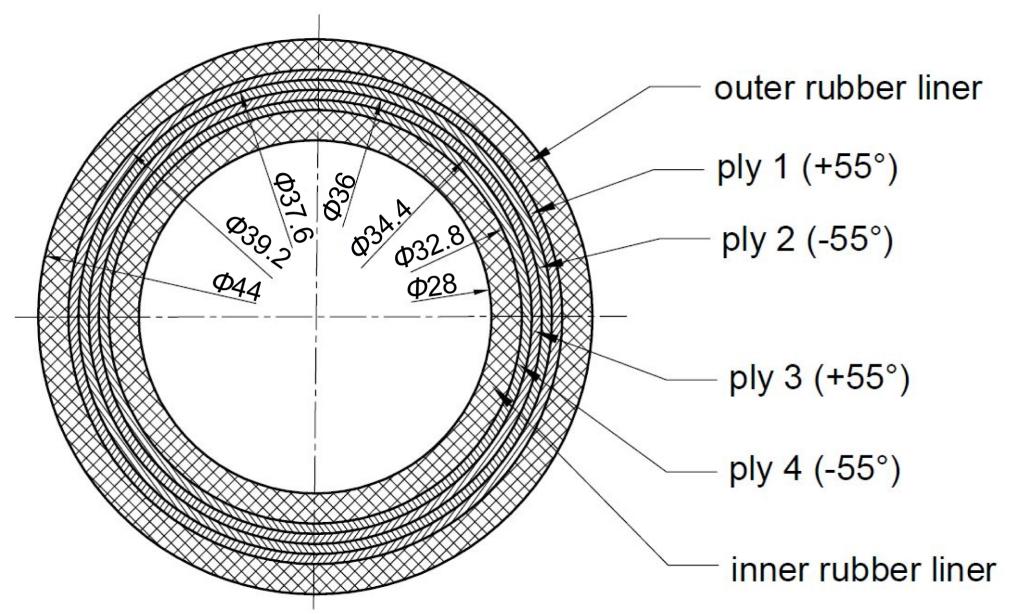

Figure 2. Cross-section of the hose [4].

$\omega$. Orientation angles of adjacent plies $\left(\alpha_{1}, \alpha_{2}\right)$ are opposite in most cases $\left(\alpha_{1}=-\alpha_{2}\right)$.

In fibre coordinate system, material direction 1 denotes direction of yarns or grainline $\left(\mathrm{x}_{1}(1)\right.$ for ply $1, \mathrm{x}_{1}(2)$ for ply 2 in Figure 1$)$, material direction 2 stands for the transverse direction within the ply $\left(\mathrm{x}_{2}(1)\right.$ for ply $1, \mathrm{x}_{2}(2)$ for ply 2 in Figure 1).

Geometry of the filament-wound composite hose can be observed in Figure 2. The hose consists of reinforcement plies and inner and outer rubber liners. Reinforcement plies can be characterized by a balanced, symmetric layup [ $+55 /$ $-55 /+55 /-55]^{\circ}{ }^{\circ}$ ] according to the manufacturer. The hose is $620 \mathrm{~mm}$ long, having an inner diameter of $28 \mathrm{~mm}$ and an outer diameter of $44 \mathrm{~mm}$.

Since composite tubes are frequently subjected to bending loads during their lifetime, bending tests are an integral part of experiments related to composite tubes. Three-point bending and four-point bending are among the most generally performed bending experiments. Firstly Lehnitskii [5] has approached the bending of cylindrically anisotropic cantilevers and has determined stress distribution in a single-layered anisotropic tube along the radius. Jolicoeur and Cardou [6] have elaborated three-dimensional solution of multi-layered aniso- 
tropic cylinders subjected to bending. Wu and Sun [7] have created a simplified theory for thin-walled beams with the use of classical laminate theory taking into account torsional warping and transverse shearing. Bending behavior of thickwalled composite tubes has been examined by Geuchy Ahmad M. I. [8] and Geuchy Ahmad M. I. and Hoa S. V. [9], giving an estimation for bending stiffness of composite tubes.

The current article is a verification of the material model of the composite hose, described thoroughly in [4], based on three-point bending and standard bending test in accordance with EN 15807:2011. The numerical model is finite element model, the utilized material model is linear orthotropic with respect to the reinforcement plies and 2 parameter Mooney-Rivlin hyperelastic model as regards rubber liners. Chapter 2 contains detailed description of three-point bending test and standard bending test, Chapter 3 presents simulation of three-point bending. Chapter 4 describes finite element model of standard bending test.

\section{Three-Point Bending and Standard Bending Experiments}

\subsection{Three-Point Bending Test}

Three-point bending test has been performed on a Zwick Z 020 tensile test machine (Figure 3). The composite hose has been placed between cylindrical bend fixtures. Diameter of the upper support is $30 \mathrm{~mm}$, diameter of the lower supports, whose vertical midplanes are situated $500 \mathrm{~mm}$ from each other symmetrically to the vertical midplane of the upper support, is $18 \mathrm{~mm}$ (Figure 4). In the course of the bending test, the upper support has descended $80 \mathrm{~mm}$.

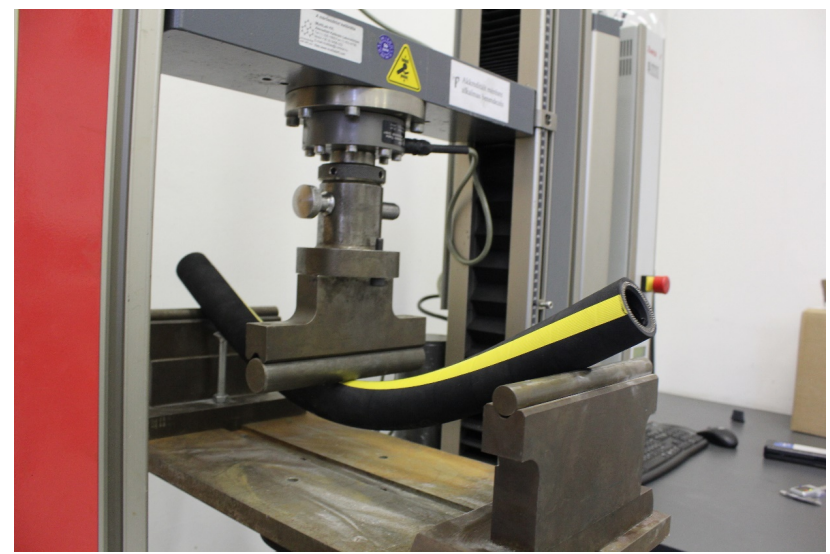

Figure 3. Three-point bending at a deflection of $80 \mathrm{~mm}$.

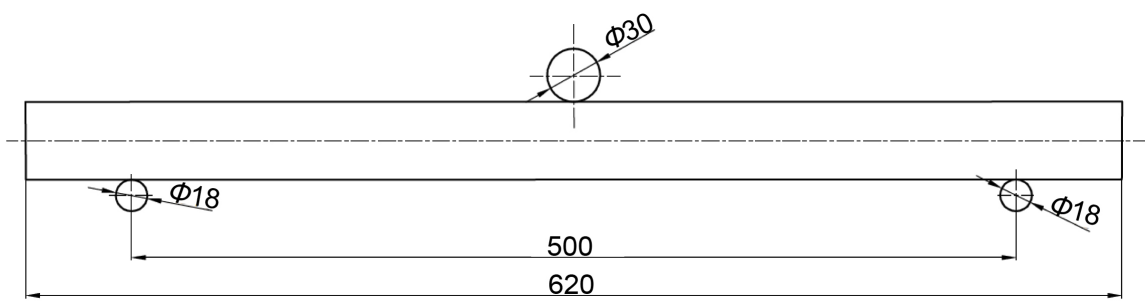

Figure 4. Disposition of the three-point bending test. 


\subsection{Standard Bending Test of the Hose onto a Disc in Accordance with EN 15807:2011}

Standard bending test of the hose onto a disc is utilized in practice as a means of quality control (Figure 5). Standard bending test has been carried out manually by bending the composite hose onto a disc, being $30 \mathrm{~mm}$ thick, having a diameter of $180 \mathrm{~mm}$. Radial reaction forces have been measured by a force gauge. Mean reaction force calculated based on 10 experimental values measured in the position depicted in Figure 5 is $121.0 \mathrm{~N}$.

\section{FE Model of Three-Point Bending}

\subsection{Material Properties of the Composite Hose}

Material of reinforcement plies is transversely isotropic, which is a special case of

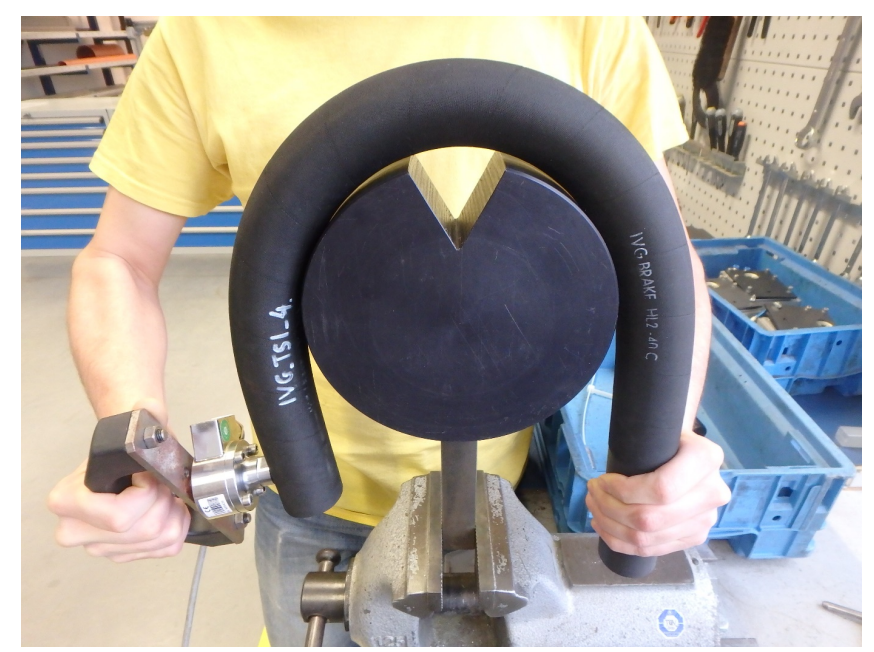

Figure 5. Measurement of radial reaction forces in the course of standard bending test.

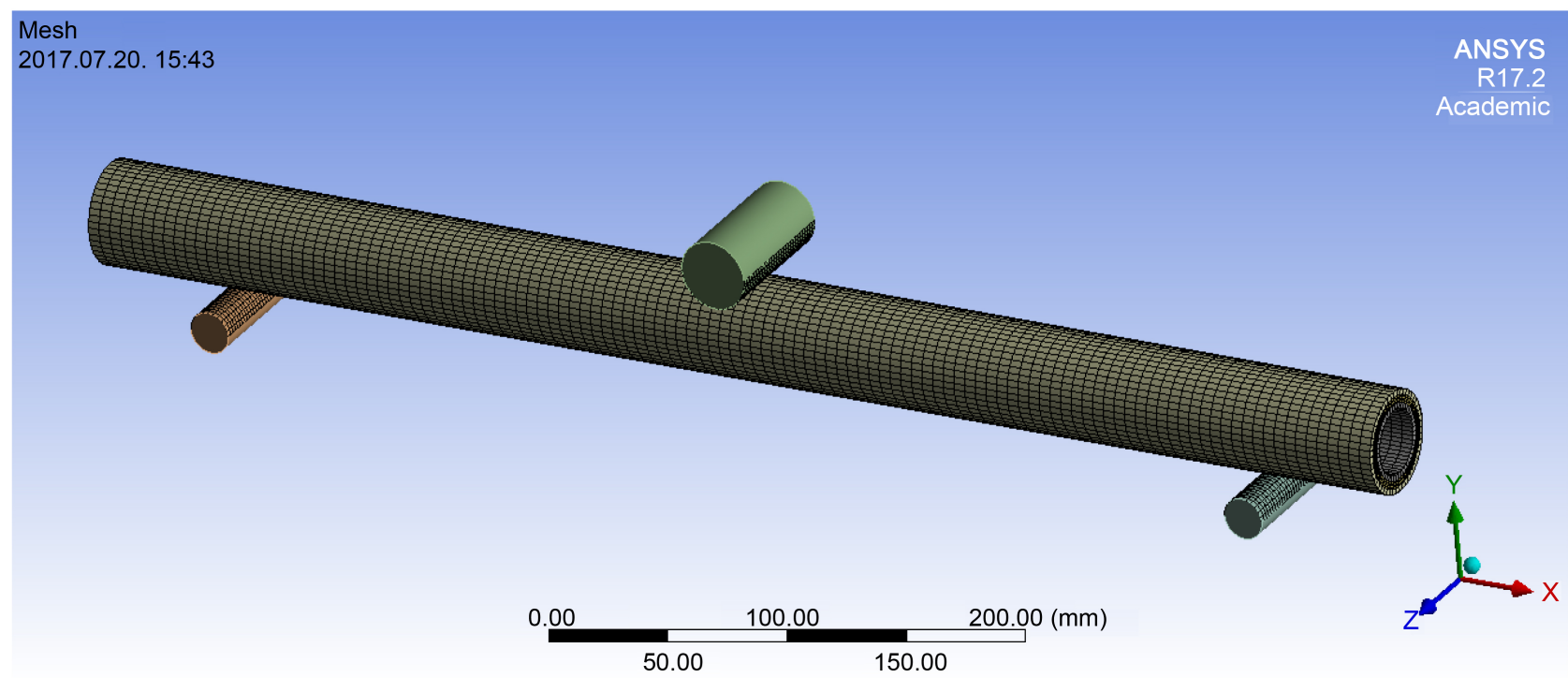

Figure 6. Disposition of FE simulation of three-point bending along with mesh. 


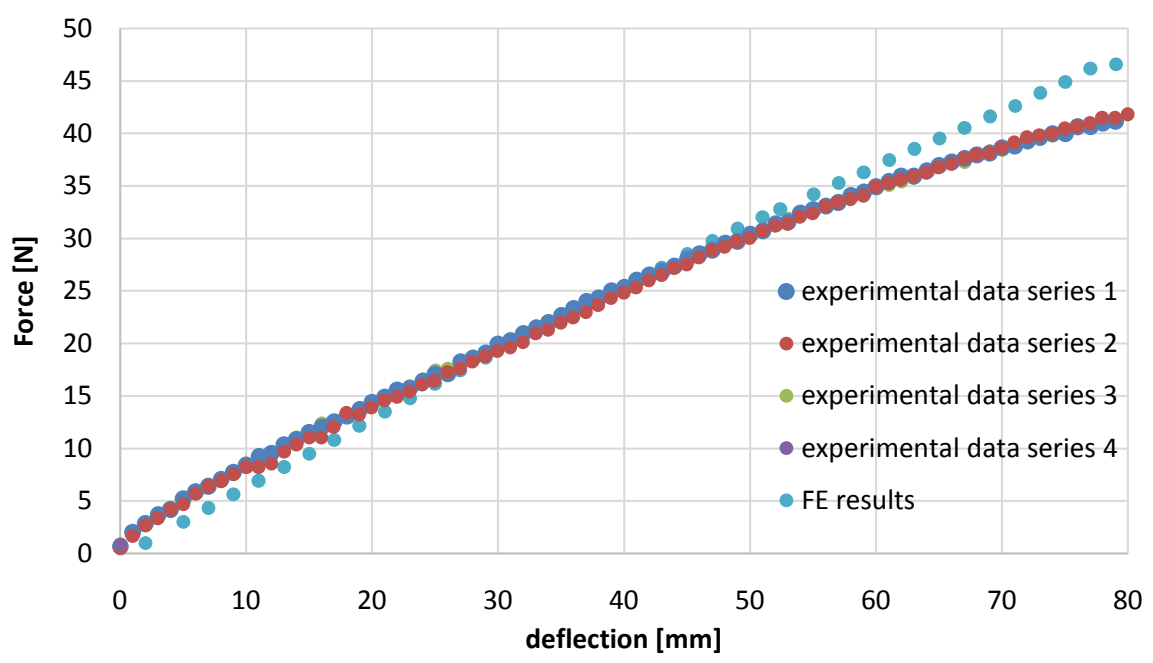

Figure 7. Force-displacement curves of three-point bending.

linear orthotropy. Orthotropic materials have three mutually perpendicular planes of symmetry, filament-wound composite hoses, with their fibres aligned uniaxially, are usually regarded as transversely isotropic because the plane perpendicular to the fibre direction is a plane of isotropy $\left(E_{2}=E_{3}, G_{12}=G_{13}, v_{12}=\right.$ $\left.v_{13}\right)$. Transversely isotropic materials have five independent elastic constants $\left(\mathrm{E}_{1}\right.$, $\left.\mathrm{E}_{2}, \mathrm{G}_{12}, \mathrm{G}_{23}, v_{12}\right)$ [10].

Material properties of components of reinforcement plies are as follows: modulus of elasticity of fibre is $E_{\mathrm{f}}=2961 \mathrm{MPa}$, Poisson's ratio of fibre is supposed to be $v_{\mathrm{f}}=0.2$, modulus of elasticity of rubber matrix is $\mathrm{E}_{\mathrm{m}}=\mathrm{E}_{\mathrm{r}}=6.14 \mathrm{MPa}$, Poisson's ratio of rubber matrix is supposed to be $v_{\mathrm{r}}=0.5$ [4].

With the use of the aforementioned parameters, material properties of reinforcement plies are as follows:

$\mathrm{E}_{1}=1338 \mathrm{MPa}, \mathrm{E}_{2}=\mathrm{E}_{3}=19 \mathrm{MPa}, \mathrm{G}_{12}=\mathrm{G}_{13}=\mathrm{G}_{23}=6 \mathrm{MPa}, v_{12}=v_{13}=0.37, v_{23}=$ $0.498[4]$.

Rubber liners are described by a 2 parameter Mooney-Rivlin model [4], whose parameters are: $\mathrm{C}_{10}=-0.4982 \mathrm{MPa}, \mathrm{C}_{01}=1.523 \mathrm{MPa}, \mathrm{D}=0[1 / \mathrm{MPa}]$, therefore the liners are considered as incompressible.

\subsection{Connections, Mesh}

There are bonded contacts between the reinforcement plies and the outer rubber liner and the reinforcement plies and the inner rubber liner respectively because rubber, being the material of the matrix and also material of inner and outer liners, is vulcanized around yarns. The contacts between the outer rubber liner and upper and lower supports are frictional with a frictional coefficient $\mu=0.8$ based on [11] and formulation "Augmented Lagrange".

Upper and lower supports are modelled as rigid bodies (Figure 6).

\subsection{Loads, Boundary Conditions}

The current FE simulation is incremental with large strains, consisting of one 
time step and several substeps. In the course of FE simulation, upper support descends $80 \mathrm{~mm}$ in global Y direction, meanwhile lower supports are fixed.

\subsection{Results}

Force-displacement curves of FE simulation and experiment of three-point bending show fairly good agreement (Figure 7) the biggest difference in forces being $10 \%$ of experimental results.

\section{FE Model of Standard Bending Test of the Composite Hose}

\subsection{Material Properties, Geometry}

Material properties of the hose are in accordance with Chapter 3.1, the geometry of the hose is presented in Chapter 2.1. Standard disc is modelled as a rigid body with a diameter of $180 \mathrm{~mm}$ and a thickness of $30 \mathrm{~mm}$. Positioning pins utilized for the bending process, placed inside the hose, are also rigid bodies, whose diameters equal the inner diameter of the hose. $70 \mathrm{~mm}$ long sections of the pins lay inside the hose. The aforementioned pins have holes, whose centers serve as a remote point for positioning the hose during the bending process, the centers of the holes are $50 \mathrm{~mm}$ from the base of the hose.

\subsection{Connections, Mesh}

Connection of inner and outer rubber liners to reinforcement plies is bonded, which is intended to model that rubber, being material of matrix and liners, is vulcanized around yarns.

Frictional contact is defined between the outer lateral surface of the hose and the disc with a coefficient of friction $\mu=0.8$ based on [11]. There are bonded contacts between the inner lateral surface of the hose and pins utilized for positioning the hose.

Disposition of the FE simulation along with mesh can be observed in Figure 8.

\subsection{Loads, Boundary Conditions}

The hose is in connection with the disc continuously during the bending process, therefore, its centreline is transformed gradually into a circle, whose radius equals the sum of the radii of the hose and the disc. In the bending process, centreline of the hose is coincident with the tangent of the above-mentioned circle (Figure 9). Therefore, the length of the hose segment not in connection with the disc decreases step by step.

Positioning of the hose is carried out by the two remote points placed at each center of hole as presented in Figure 8. Positions of the right half of the hose in each time step are shown in Figure 9, while positions of the right remote point represented by global X and $\mathrm{Y}$ coordinates can be seen in Figure 10. The prescribed trajectory ensures that there is no reaction force in the tangential direction at the current point of tangency on the disc, therefore the finite element 


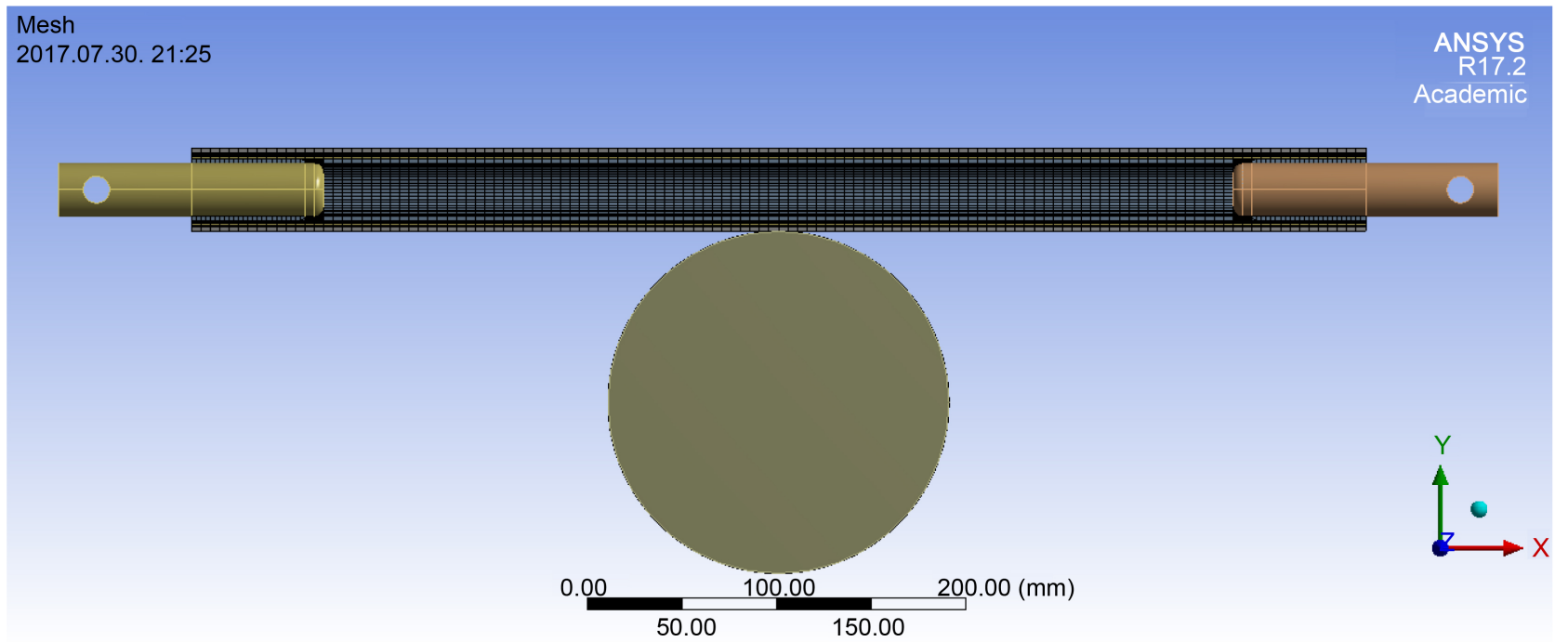

Figure 8. Disposition of the FE simulation along with mesh.

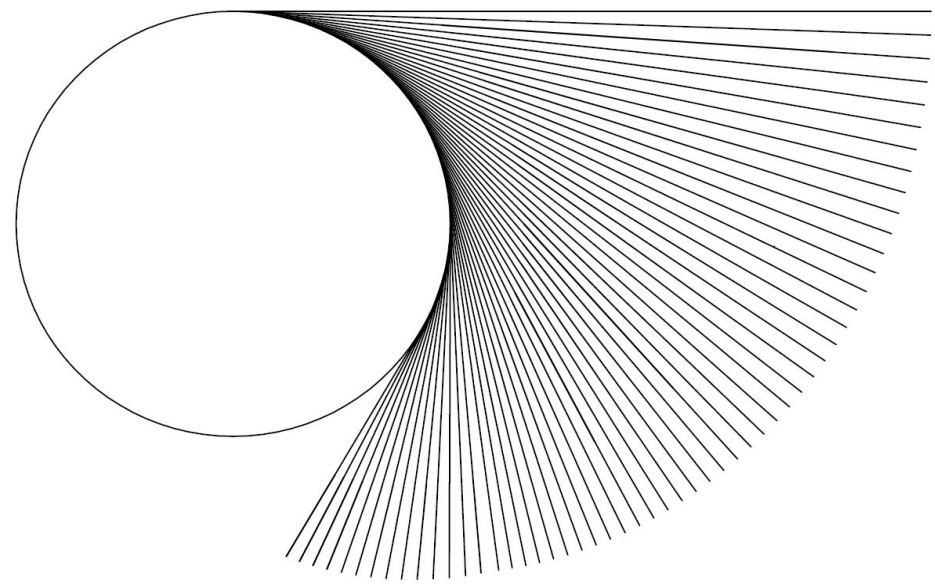

Figure 9. Position of the right half of the hose in each time step.

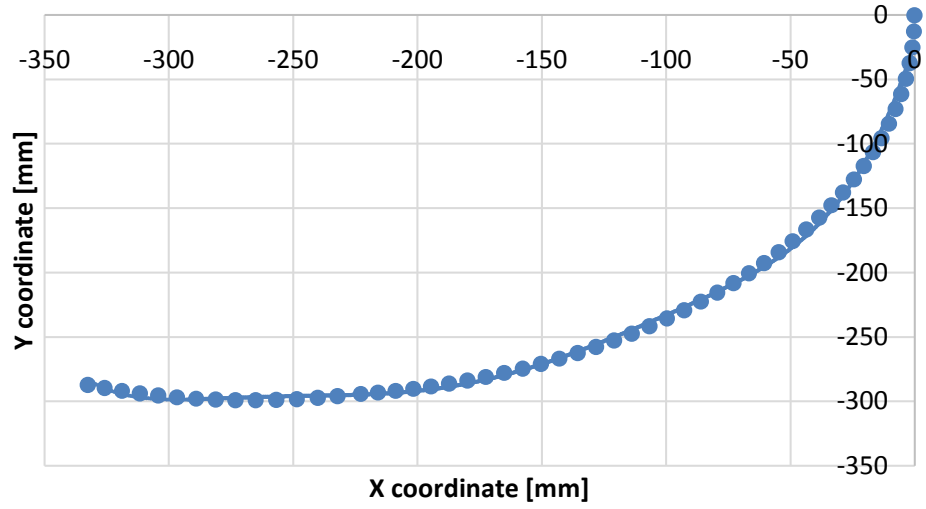

Figure 10. Position of the right remote point in each time step.

bending process is smooth enough. Positions of the left remote point are symmetric to the positions of the right remote point in every time step, the plane of symmetry is the global $\mathrm{YZ}$ plane. Translation of remote points in direction $\mathrm{Z}$ is 
not allowed, rotation around axes $\mathrm{X}$ and $\mathrm{Y}$ is not allowed either, however, rotation around axis $\mathrm{Z}$ is possible.

In the current FE model, the disc is completely fixed.

\subsection{Results}

Mean radial reaction force disclosed in Chapter 2 is $121.0 \mathrm{~N}$ in the position depicted in Figure 5, in this position in the FE simulation, the radial reaction force at the connection of the inner rubber liner and the positioning pin is $122.5 \mathrm{~N}$. Hence, experimental and simulation results show good agreement. Position of the hose while measuring radial reaction force in simulation and during the experiment is apparently the same (Figure 11 and Figure 5 respectively).

Figures 12-14 show the strain state in the outermost reinforcement ply (ply1) at the end of the standard bending test. The strains in material direction 1 are not significant due to the high modulus of elasticity in that direction (Figure 12).

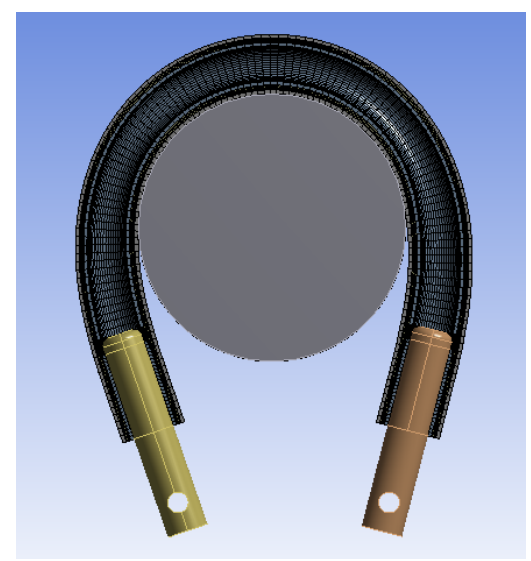

Figure 11. Position of the hose for obtaining radial reaction force.

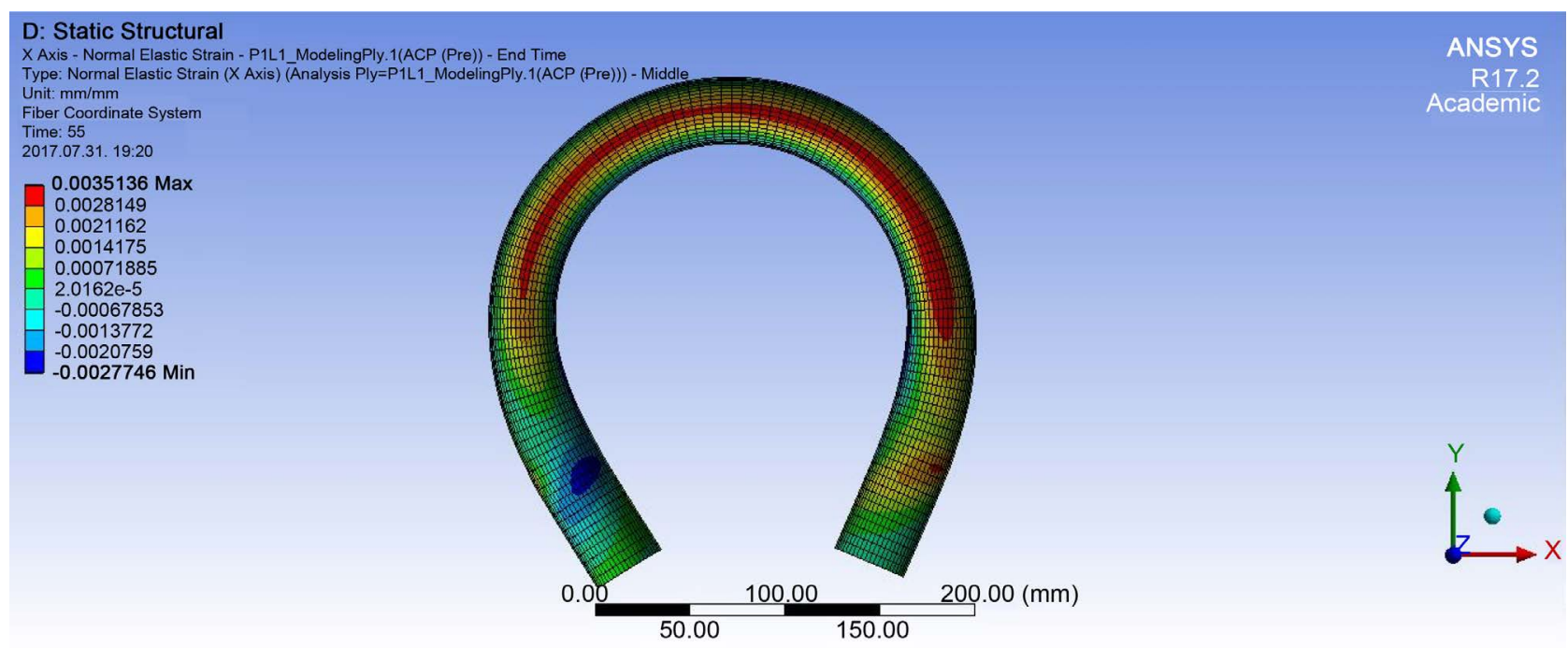

Figure 12. Normal strain in material direction $1\left(\varepsilon_{1}\right)$ in fibre coordinate system, ply 1 at the end of the standard bending test, longitudinal section in midplane $\mathrm{XY}$. 


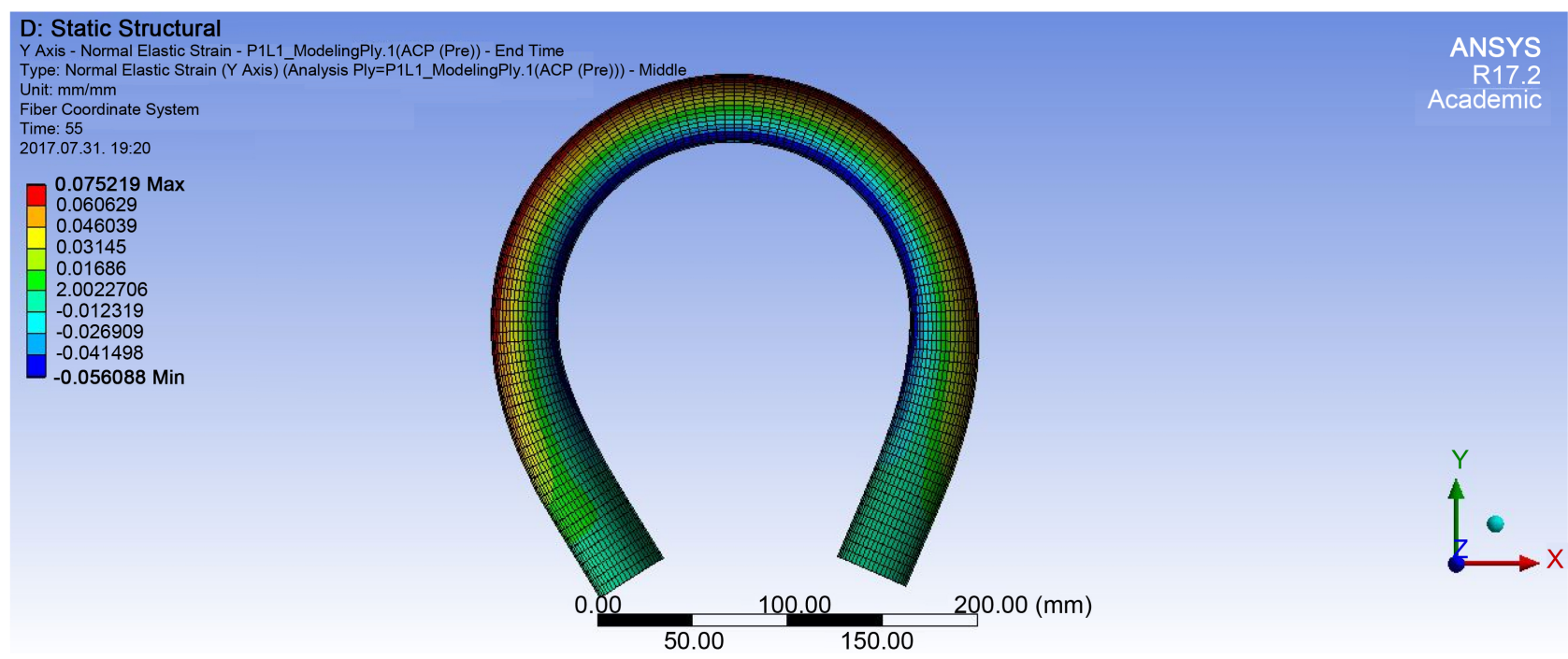

Figure 13. Normal strain in material direction $2\left(\varepsilon_{2}\right)$ in fibre coordinate system, ply1 at the end of the standard bending test, longitudinal section in midplane XY.

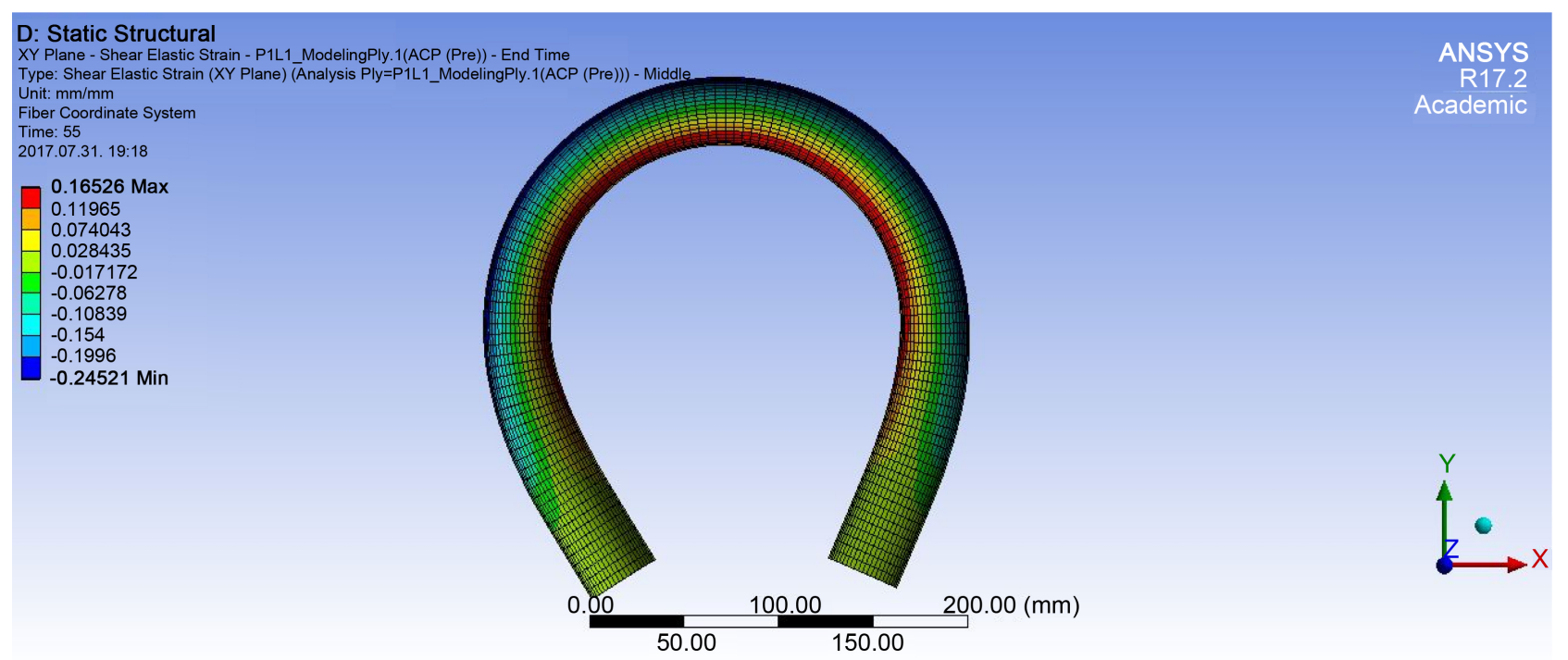

Figure 14. Shear strain in plane $12\left(\gamma_{12}\right)$, in fibre coordinate system, ply1 at the end of the standard bending test, longitudinal section in midplane XY.

Modulus of elasticity is lower in material direction 2, so Figure 13 shows higher strain values in material direction 2 . The strain component having the highest values is shear strain, shown in Figure 14, which is a result of shear-extension coupling [12], being a typical feature of composite layers.

Table 1 shows maximal strains for each reinforcement ply. It can be seen that approximately equal strains are present in plies. Shear strains have opposite signs in adjacent plies, this can be attributed to the balanced layup of the hose (orientation angle of adjacent plies are $\pm \omega$ ).

Figures 15-17 show stress state in ply1 at the end of the standard bending test. Maximal stresses are present in material direction 1 according to Figure 15, because mostly yarns bear the load exerted from bending. Normal stress in material 
Table 1. Maximal strainsin reinforcement plies in fibre coordinate system, ply1.

\begin{tabular}{cccc}
\hline Ply no. & $\varepsilon_{1}[-]$ & $\varepsilon_{2}[-]$ & $\gamma_{12}[-]$ \\
\hline 1 & 0.0035 & 0.075 & -0.2452 \\
2 & 0.0035 & 0.076 & 0.2313 \\
3 & 0.0027 & 0.072 & -0.221 \\
4 & 0.0029 & 0.073 & 0.206 \\
\hline
\end{tabular}

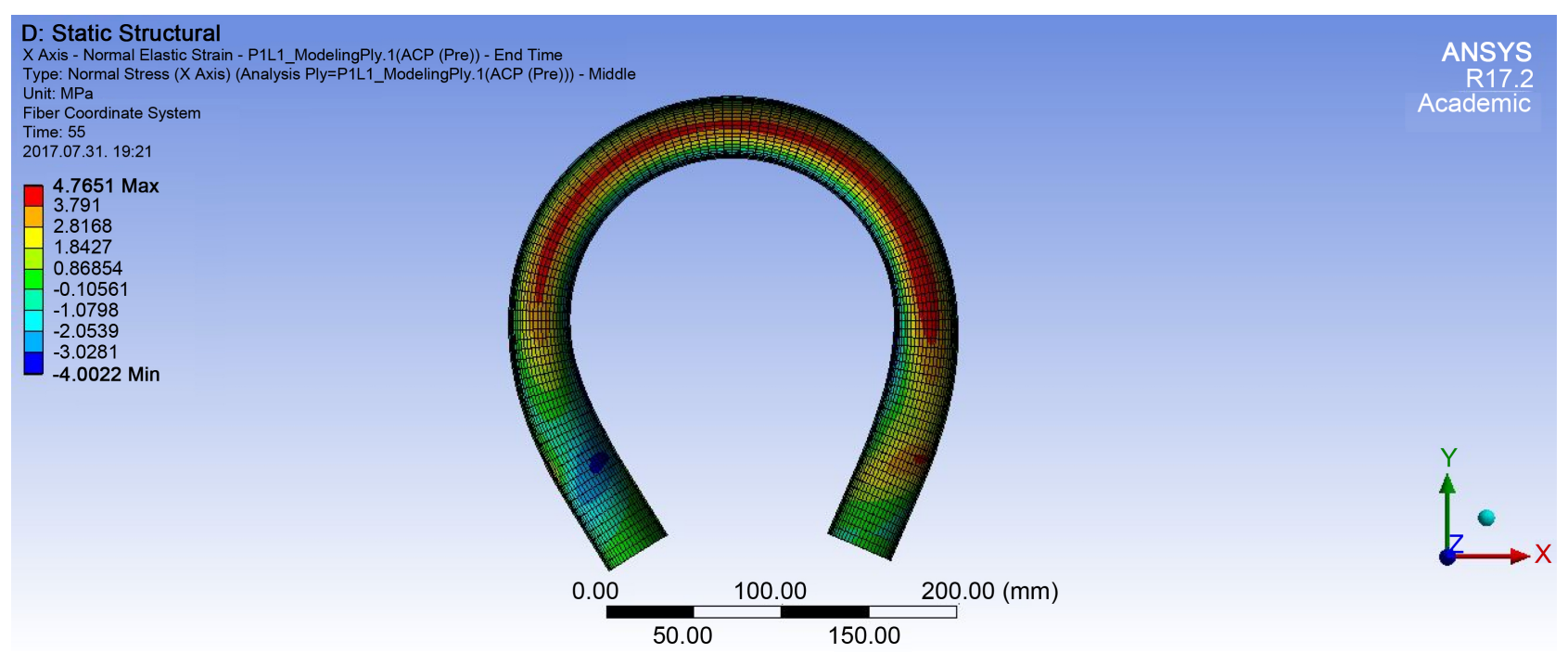

Figure 15. Normal stress in material direction $1\left(\sigma_{1}\right)$, in fibre coordinate system, at the end of the standard bending test, longitudinal section in midplane XY.

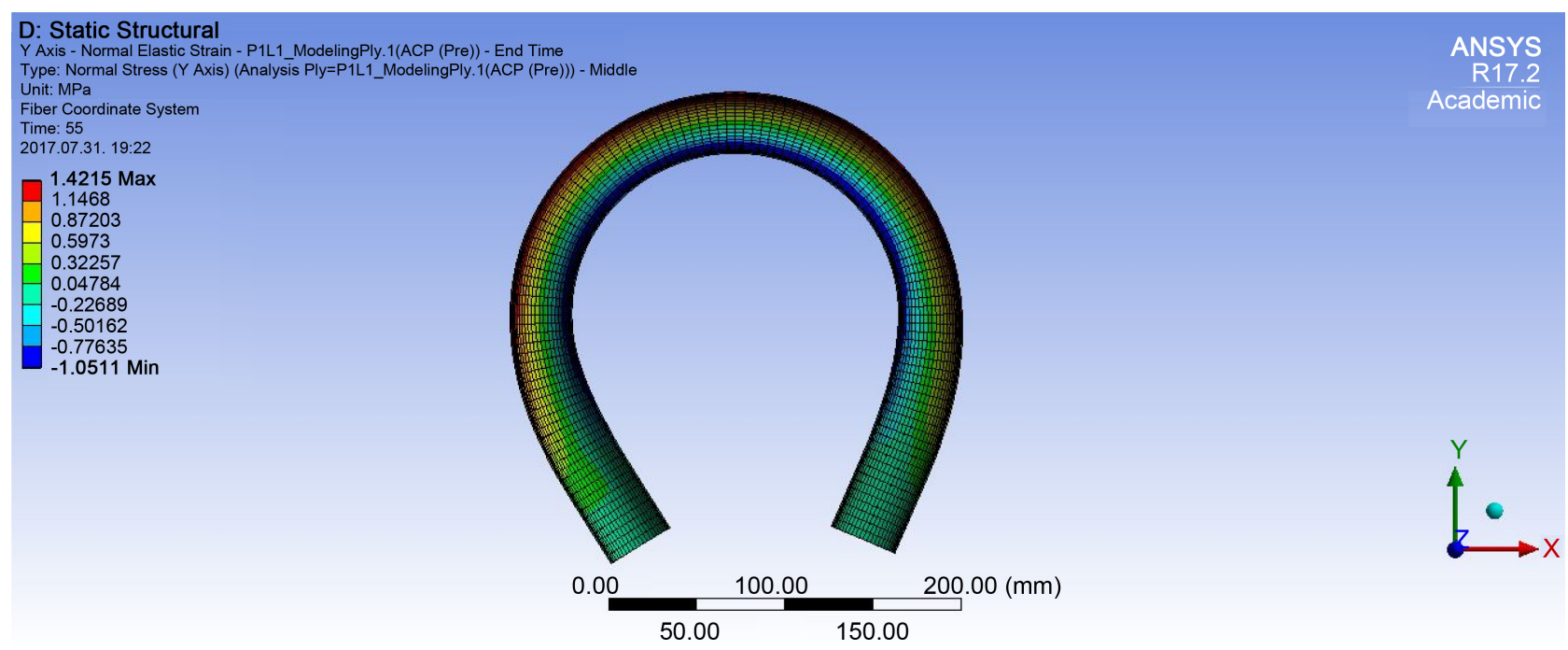

Figure 16. Normal stress in material direction $2\left(\sigma_{2}\right)$, in fibre coordinate system, at the end of the standard bending test, longitudinal section in midplane $\mathrm{XY}$.

direction 2 and shear stress in plane 12 are shown in Figure 16 and Figure 17 respectively. Although these components are not negligible either, they have a magnitude considerably lower compared to normal stress in fibre direction.

Load is distributed nearly equally among reinforcement plies (Table 2), pre 


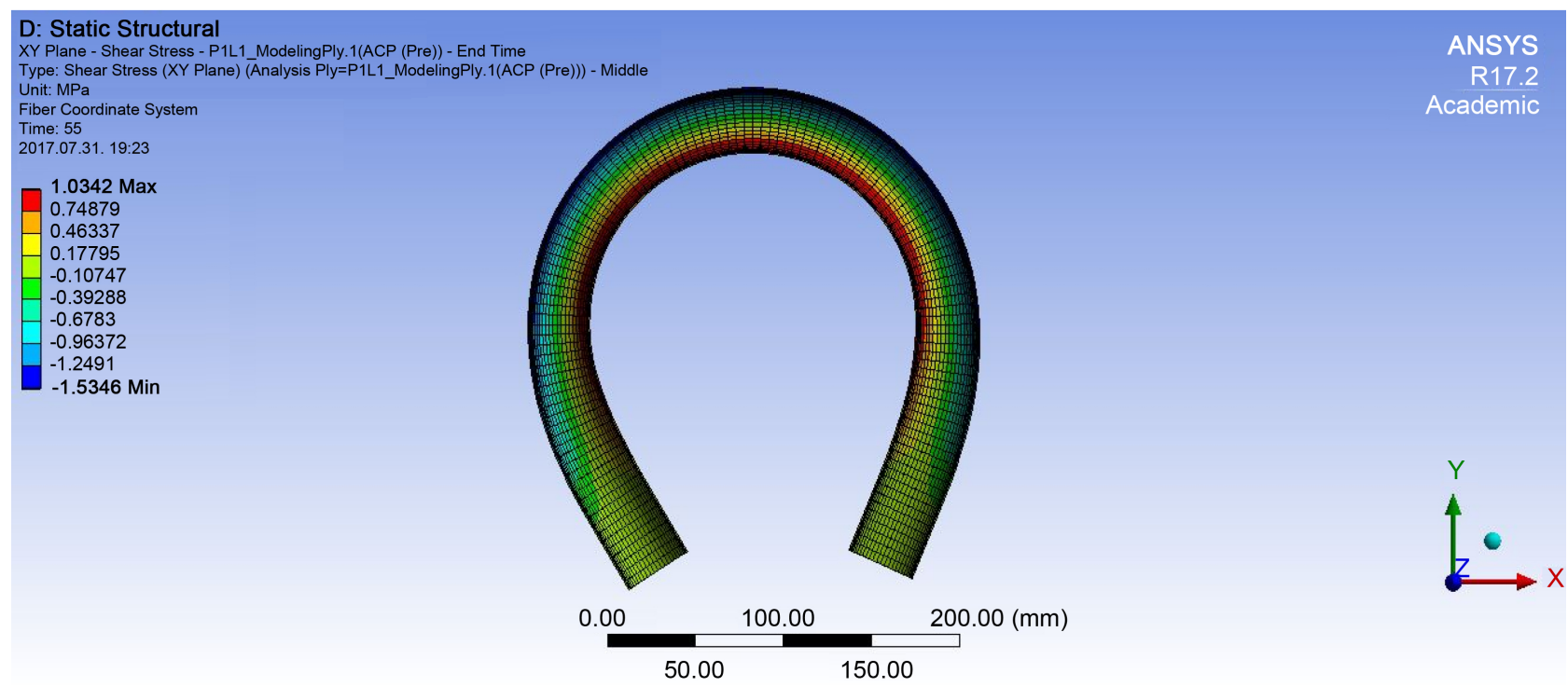

Figure 17. Shear stress in plane $12\left(\tau_{12}\right)$, in fibre coordinate system, at the end of the standard bending test, longitudinal section in midplane XY.

Table 2. Maximal stresses in reinforcement plies in fiber coordinate system, ply1.

\begin{tabular}{cccc}
\hline Ply no. & $\sigma_{1}[-]$ & $\sigma_{2}[-]$ & $\tau_{12}[-]$ \\
\hline 1 & 4.77 & 1.42 & -1.535 \\
2 & 4.75 & 1.47 & 1.45 \\
3 & 5.62 & 1.43 & -1.38 \\
4 & 5.31 & 1.42 & 1.29 \\
\hline
\end{tabular}

dominant role of normal stress in material direction 1 is confirmed. Shear stresses, like shear strains, are approximately equal in adjacent plies although having opposite signs. This is realized due to adjacent plies having opposite orientation angles $( \pm \omega)$.

\section{Conclusions}

Experimental data series and FE simulation results of three-point bending show good agreement regarding force-displacement curves.

In case of standard bending test, reaction forces acquired from the simulation are in good agreement with experimental reaction forces. Mechanical behavior of composite tube subjected to standard bending test has been demonstrated based on stress and strain states of the FE model.

\section{Acknowledgements}

Authors show gratitude to Department of Polymer Engineering, Budapest University of Technology and Economics, namely to Gábor Szebényi for providing them with the testing environment. The recent study and publication was realized within the Knorr-Bremse Scholarship Program supported by the Knorr- 
Bremse Rail Systems Budapest.

\section{References}

[1] Xia, M., Takayanagi, H. and Kemmochi, K. (2001) Analysis of Multi-Layered Filament-Wound Composite Pipes under Internal Pressure. Composite Structures, 53, 483-491. https://doi.org/10.1016/S0263-8223(01)00061-7

[2] Almeida Jr., J.H.S., Ribeiro, M., Volnei, T. and Amico, S.C. (2017) Damage Modeling for Carbon Fiber/Epoxy Filament Wound Composite Tubes under Radial Compression. Composite Structures, 160, 204-210. https://doi.org/10.1016/j.compstruct.2016.10.036

[3] Rosenow, K. (1984) Wind Angle Effects in Glass Fibre-Reinforced Polyester Filament Wound Pipes. Composites, 15, 144-152. https://doi.org/10.1016/0010-4361(84)90727-4

[4] Szabó, G., Váradi, K. and Felhős, D. (2017) Finite Element Model of a Filament-Wound Composite Tube Subjected to Uniaxial Tension. Modern Mechanical Engineering, 7, 91-112. https://doi.org/10.4236/mme.2017.74007

[5] Lekhnitskii, S.G. (1981) Theory of Elasticity of an Anisotropic Body. MirPublishers, Moscow.

[6] Jolicoeur, C. and Cardou, J. (1994) Analytical Solution for Bending of Coaxial Orthotropic Cylinders. Journal of Engineering Mechanics, 120, 2556-2574. https://doi.org/10.1061/(ASCE)0733-9399(1994)120:12(2556)

[7] Wu, X.X. and Sun, C.T. (1992) Simplified Theory for Composite Thin-Walled Beams. AIAA Journal, 30, 2945-2951. https://doi.org/10.2514/3.11641

[8] Geuchy Ahmad, M.I. (2013) Bending Behaviour of Thick-Walled Composite Tubes. PhD Thesis, Concordia University, Concordia.

[9] Geuchy Ahmad, M.I. and Hoa, S.V. (2016) Flexural Stiffness of Thick Walled Composite Tubes. Composite Structures, 149, 125-133. https://doi.org/10.1016/j.compstruct.2016.03.050

[10] Chawla, K.K. (2009) Composite Materials Science and Engineering. 3rd Edition, Springer, Print, New York, London.

[11] Karger-Kocsis, J., Mousa, A., Major, Z. and Békési, N. (2008) Dry friction and Sliding Wear of EPDM Rubbers against Steel as a Function of Carbon Black Content. Wear, 264, 359-367. https://doi.org/10.1016/j.wear.2007.03.021

[12] Jones Robert, M. (1999) Mechanics of Composite Materials. 2nd Edition, CRC Press, Print, Philadelphia. 